\title{
Increasing nuclear power at liberalised energy markets- case Finland
}

\author{
S. Syri ${ }^{1, a}$, T. Kurki-Suonio ${ }^{2}$, and V. Satka ${ }^{1}$ \\ ${ }^{1}$ Aalto University, School of Engineering, FIN-00076 Aalto, Finland \\ 2 Aalto University, School of Science, FIN-00076 Aalto, Finland
}

\begin{abstract}
Several Finnish projections for future electricity demand and the need for peak load capacity indicate a demand growth of about $2 \mathrm{GW}$ from the present to the year 2030 . The retirement of existing fossil fuel plants and old nuclear power plants will cause increased net import needs during 2020's, even when assuming additional energy efficiency measures and the commissioning of two new nuclear power plants recently approved by the Finnish Parliament. By the year 2030, the need for additional new capacity will be about $6 \mathrm{GW}$. The increased dependence on import is in contradiction with the official Government targets. This situation is not unique to Finland, but rather is likely to be the case in many other European countries as well. Both the energy company Fortum and energy-intensive industry in Finland see nuclear energy as a viable future generation technology. We describe the « Mankala» concept which is successfully used to build new nuclear capacity at liberalised electricity market in Finland.
\end{abstract}

\section{Introduction}

The Nordic electricity markets were liberalised in the 1990's and they constitute one of the world's first multi-national liberalised electricity markets [1]. The Nordic market is characterized by a large share of both hydro and nuclear power. Therefore, the specific carbon dioxide $\left(\mathrm{CO}_{2}\right)$ emissions from power generation are small. As part of the EU, Finland faces challenging targets for further reduction of $\mathrm{CO}_{2}$ emissions and increase of renewable energy.

The Finnish economy is exceptionally dependent on energy-intensive export industry in comparison to the EU or the OECD average situation. This is also the main reason why the per capita electricity consumption in Finland is considerably above the EU and OECD averages. The share of all national $\mathrm{CO}_{2}$ emissions falling under the EU emissions trading scheme was $62 \%$ in the beginning of the scheme, whereas the EU average was 55\% [2]. Therefore, the Finnish industry has been quite concerned about possible high future $\mathrm{CO}_{2}$ prices, which directly increase the market prices of electricity.

In Finland, the joint investments of energy-intensive industry in large-scale energy production have a long tradition, starting from the electricity needs of the forest industry in 1930's and 1940's. The so-called "Mankala" principle means that companies that needed a large, stable energy supply,

\footnotetext{
a e-mail : sanna.syri@aalto.fi
} 
but did not themselves have the capacity to construct and run power plants, founded together a company to construct and operate power plants and sell energy to the shareholders at cost price instead of giving dividend.

This model seems to be successful also in realizing large nuclear power investments in today's liberalised electricity markets, contrary to the often heard statement that at free electricity markets, nuclear power is not constructed due to the large investment costs and related risks seen by financing institutions. In Finland, there are four nuclear power reactors in operation and a fifth reactor is under construction. The company TVO operates two nuclear reactors at Olkiluoto since 1978 and 1980, and the 1600 MW EPR reactor "OL3" [3], built by Areva, is currently under construction, with estimated start of electricity production to the grid in Autumn 2014. In addition, Fortum Ltd. operates two nuclear reactors in Loviisa [4]. In July 2010, the Finnish parliament gave positive decision-inprinciple for two additional units, one applied by TVO and the other by a newcomer, Fennovoima. These are both companies owned by groups of energy generation companies and energy-intensive industry. There was also a third application by Fortum Ltd. to replace the aging Loviisa nuclear plants, but the Finnish parliament did not approve Fortum's application.

In this paper, we analyse the future development of Finnish power generation capacity in relation to electricity demand trends. The substantial increase of nuclear power and renewables will only temporarily be able to satisfy the demand in spite of additional energy efficiency measures.

\section{Future projections of generation capacity and demand in Finland}

The future development of power plant capacity is analysed with a database that contains all major power plants and all established new construction plans in Finland including reserve power. The estimated decommissioning is based on the year of construction and typical lifetime of the power plant type, i.e. 40 years for condensing plants, 50 years for combined heat and power (CHP) plants and the existing nuclear plants. The latter corresponds to the present decommissioning plans for Loviisa I and II in 2027 and 2030. In Olkiluoto, the present operation permits for OL1 and OL2 are valid until 2018, and it is very likely that TVO will apply for 10-20 years extension.

Concerning hydropower, we assume that the existing capacity would be constantly maintained and replaced, so that there would not be any net decrease of hydro capacity. It is estimated that 2.5 GW hydro capacity, corresponding about $80 \%$ of total installed hydro capacity in Finland, would be available during the peak load as hydro production can face different restrictions and so all capacity will not be available even if needed.

Concerning windpower, we utilise the capacity credit modelling developed at Aalto University [5]. It is assumed that wind power capacity will reach approximately $1.5 \mathrm{GW}$ in 2020 and $3 \mathrm{GW}$ in 2030. The official government target is $6 \mathrm{TWh}$, i.e. about $2.5 \mathrm{GW}$ of capacity, of windpower by 2020 , and to meet this target, a feed-in tariff has been introduced. The present construction rate is lagging far behind this target, as the licencing procedures to obtain construction permit have been unexpectedly slow, partly due to complaint procedures. When available wind generation capacity during the peak load is estimated, the capacity value (effective load carrying capability, ELCC) is used. For a low level of wind capacity it is about $20 \%$ and for $3 \mathrm{GW}$ of capacity it is $11 \%$.

We assume that the new nuclear plants OL4 of TVO and the Fennovoima plant would each have a generation capacity of $1.6 \mathrm{GW}$, and commence operation in 2020 and 2022, correspondingly.

We compared the available future capacity to three recently compiled peak load estimations that cover the years 2010-2030 [6-8]. The estimations made by different organizations help to analyse what will be the need for electricity generation capacity in the future. The estimates assume continuation of the present energy efficiency incentives in all sectors of the Finnish economy.

Figure 1 shows the development of the electricity generation capacity in relation to the peak load demand in Finland with these assumptions. 


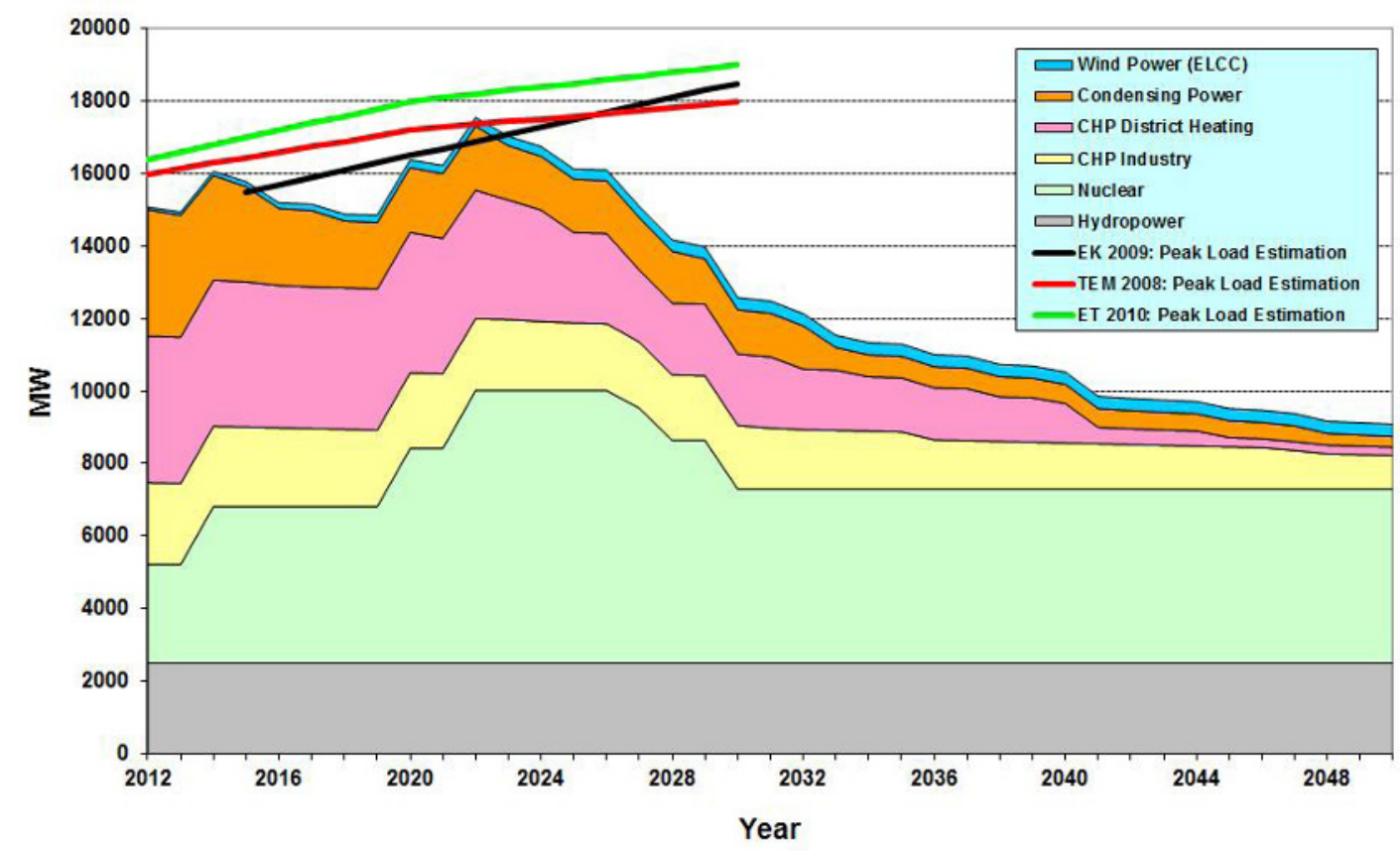

Fig. 1. Development of the electricity generation capacity and peak load demand in Finland.

The recent Finnish projections for future electricity demand and the need for peak load capacity indicate a demand growth of about $2 \mathrm{GW}$ from the present to the year 2030. The retirement of existing fossil fuel plants and old nuclear power plants will cause increased net import needs during 2020's, even when assuming additional energy efficiency measures and the commissioning of the two new nuclear power plants. By the year 2030, the need for additional new capacity will be about $6 \mathrm{GW}$.

The baseload power in Finland will increasingly consist of nuclear power and hydro power. As CHP uses fuel significantly more efficiently than condensing power, it would be desirable to maintain its share in the power system. Even if we assumed that aging district heating CHP plants would be replaced with corresponding new CHP plants, perhaps using more biomass-based fuels than their predecessors, the gap between available peak load capacity and demand would be 3-4 GW.

All recent Finnish government strategies aim at reducing import dependence in net electricity generation and having sufficient domestic generation capacity to cover also the peak load demand. Finland has steadily imported a sizeable share of electricity generation from Russia. There is a oneway transmission connection with a capacity of $1.4 \mathrm{GW}$ from the St. Petersburg area to South Eastern Finland, and this has usually been used with maximum capacity during Winter peak load times. However, recently the situation has changed due to the re-structuring of the Russian electricity markets. As the electricity market prices in Russia have increased due to the market reform, it is not anymore at all times profitable for generators in the St. Petersburg area to export electricity to Finland.

It should be noted that the demand estimates used [6-8] do not cover all possible future electricity demand changes due to possible structural changes in the Finnish economy. The estimates are made in 2007-09, so they do not cover the latest developments either. Factors possibly increasing electricity demand further are for instance large data centres entering Finland, such as the recent Google investment in a new data centre to Hamina in Southern Finland. The Finnish regional and municipal authorities are actively campaigning to attract more data centres to Finland. This is because Nordic Countries have several favourable features to offer, including a relatively cheap and stable electricity price and easily available cooling. 
Another recent trend not included in [6-8] is the increasing mining industry activity in Northern Finland. Talvivaara nickel mine started full-scale operation in 2011. The estimated annual electricity consumption at full capacity is $1.9 \mathrm{TWh}$. A gold mine was opened in 2012 in Raahe region and there are several other large-scale mining activities currently planned.

Correspondingly, the future of forest industry in Finland has a large impact on both energy consumption and on the possibilities to further increase the share of renewable energy. The majority of industrial CHP production in Finland takes place in connection to forest industry. The recent trend has been that the forest industry has closed down aging paper mills in Finland due to overcapacity at the international markets and resulting profitability problems. The future domestic production trends estimated in [7-8] may be too optimistic, as they assume continued growth of forest industry in Finland, with electricity consumption increasing from the present about $27 \mathrm{TWh}$ to $32 \mathrm{TWh}$ by 2030 .

\section{Nordic electricity market}

Table 1 shows the generation structure of the whole Nordic electricity market in 2010 and changes from 1998 by generation type. The year 2010 was a dry year at the Nordic market, with a deficit of hydropower reservoirs of $30 \mathrm{TWh}$ compared to the average year.

Table 1. Power generation (TWh) in the Nordic countries in 2010, according to preliminary national statistics, and changes from $1998(\%)$ [9-12].

\begin{tabular}{|c|c|c|c|c|c|}
\hline & Finland & Sweden & Norway & Denmark & Total \\
\hline Total & 77,2 & 145 & 124 & 38,6 & 385 \\
production & $14,6 \%$ & $-6,1 \%$ & $6,4 \%$ & $-1,2 \%$ & $2 \%$ \\
\hline Hydro & 12,7 & 55,5 & 118 & - & 197 \\
power & $-12,5 \%$ & $-21,1 \%$ & $1,4 \%$ & & $-3,8 \%$ \\
\hline Nuclear & 21,9 & 55,6 & - & - & 77,5 \\
power & $4,2 \%$ & $-21,1 \%$ & & & $-15,3 \%$ \\
\hline Thermal & 42,1 & 19,7 & 5,61 & 30,8 & 98,2 \\
power & $31,6 \%$ & $100 \%$ & $740 \%$ & $-15,4 \%$ & $25,1 \%$ \\
\hline Wind power & 0,3 & 3,5 & 5,61 & 7,8 & 12,5 \\
& $994 \%$ & $1070 \%$ & $11000 \%$ & $194 \%$ & $318 \%$ \\
\hline
\end{tabular}

The unusually dry and cold year 2010 resulted in exceptionally large use of conventional generation. The apparently decreasing trend in Swedish nuclear generation is due to reduced availability of the existing capacity in 2010 .

During the past decade, wind power capacity in the Nordic countries has increased strongly in the Nordic countries, Denmark having been the forerunner.

A specific recent feature of the Nordic market are the substantial windfall profits induced to the owners of hydro and nuclear power. Most of the time the spot market price is set by the variable costs of coal condensing power. Thus hydro and nuclear power, sold at the spot market, receive the price increase caused by the $\mathrm{CO}_{2}$ cost to condensing coal power. This windfall profit has been estimated to be in the order of 2 billion $\left(10^{9}\right) € / \mathrm{yr}$ at the Nordic market at the $\mathrm{CO}_{2}$ price of $10 € /$ tonne [2]. This estimate excludes "Mankala" power generation, which is mostly sold directly to owners at cost price.

\section{The Mankala-principle: joint ownership of large generation capacity}

Finnish energy-intensive companies see ownership of electricity production as an important means of protection against the increasing prices and volatility at the liberalised electricity markets. 
The impacts of $\mathrm{EU} \mathrm{CO}_{2}$ emissions trading on electricity prices can be large and difficult to predict, as the first trading periods since 2005 have shown.

In the 1960's, the share of industry in total electricity consumption in Finland was already $60 \%$. TVO was founded in 1969, with the purpose of bringing knowledge on nuclear energy generation to its industrial shareholders and building nuclear power for the shareholder use. TVO's Olkiluoto I and II started operation in 1978 and 1980, correspondingly.

In the 1990's, industry saw again an increasing need of electricity. The TVO application for a new nuclear power plant was rejected by the Finnish parliament in 1993. In 2002, the renewed application was given a positive decision-in-principle. At present, concern over the impacts of increased $\mathrm{CO}_{2}$ prices on the energy prices has become an increasingly important driver in industry's decisions.

Table 2 shows the ownership of TVO. Most energy companies, such as EPV Energy Ltd. are also joint ownerships of other small- and medium size energy companies. Karhu Power Ltd., in turn, is owned by E.ON Ltd. The largest single owners of TVO are Fortum Power and Heat Ltd. $(25,9 \%)$ and the pulp and paper company UPM Ltd $(25,2 \%)$. The state of Finland is the majority shareholder in Fortum with a share of about $51 \%$.

Table 2. The ownership of TVO.

\begin{tabular}{|l|r|}
\hline EPV Energy Ltd. & $6,5 \%$ \\
\hline Fortum Power and Heat Ltd. & $25,9 \%$ \\
\hline Karhu Power Ltd. & $0,1 \%$ \\
\hline Kemira Ltd. & $1,0 \%$ \\
\hline Mankala Ltd. & \multicolumn{2}{|l|}{$8,1 \%$} \\
& \\
\hline Pohjolan Voima (PVO) Ltd. & $58,4 \%$ \\
of which : & $14,8 \%$ \\
Stora Enso Ltd & $43,1 \%$ \\
UPM-Kymmene Ltd. & $3,9 \%$ \\
Kemira Ltd. & $4,1 \%$ \\
Ilmarinen (pension insurance company) & $4,6 \%$ \\
other energy-intensive industry & $21,7 \%$ \\
other energy companies & $7 \%$ \\
cities (Oulu, Kokkola, Helsinki, Pori) & \\
\hline
\end{tabular}

Fennovoima was founded in 2007 and it does not have any other generation than the planned nuclear reactor. The largest owner of Fennovoima (34\%) is E.ON Kärnkraft Finland Ltd. Finnish energyintensive industry and major companies of retail trade (Kesko Ltd., SOK) and food industry (Myllyn paras Ltd., Atria Ltd., Valio Ltd.) form another third of the ownership, and small- and medium-size regional energy companies form the last third of the ownership. There are altogether 69 Finnish companies forming $66 \%$ of Fennovoima ownership, i.e. there are about 60 municipal-size energy companies participating in Fennovoima.

E.ON obviously sees the Fennovoima shareholdership as a possibility to strengthen its position at the Nordic market. For Fennovoima, in turn, E.ON's knowledge in nuclear power operation is valuable.

The stainless steel company Outokumpu Ltd. is the largest single shareholder in Fennovoima after E.ON. Outokumpu Tornio works is the largest single electricity consumer in Finland, and a stable electricity price is crucial for the competitiveness of steel production in Tornio. After the completion of the new chromium mining unit, the annual electricity consumption of the Tornio site 
will increase to $3.3 \mathrm{TWh}$ from the present $2 \mathrm{TWh}$. Outokumpu has also long-term plans to double its stainless steel production at Tornio, and its recent acquisition of INOXUM may strengthen this development.

\section{Discussion and Conclusions}

It is often said that nuclear power is such a capital-intensive form of generation that constructing it is not competitive at liberalised electricity markets. In addition, as a reaction to the Fukushima accident, in many Western countries political decisions have been made during 2011 to cancel earlier plans of maintaining and constructing nuclear power. In Europe, these include the decision of Germany to abandon nuclear power by 2022 and the related immediate closing of seven oldest operating reactors, the decision of Switzerland to abandon nuclear power by the 2030's and the abandonment of construction plans in Italy.

In contrast to these central European developments, Finland is a part of the liberalised Nordic electricity market and the main electricity generations companies want to construct nuclear power. Two new positive decisions-in-principle have been given in 2010 by the Finnish Parliament, and the third application aiming at replacing the aging Loviisa plants by Fortum Ltd. was rejected. TVO and Fennovoima are proceeding with their projects according to the original plans.

Nuclear power has provided an important source of $\mathrm{CO}_{2}$-free electricity in countries that have made post-Fukushima decisions to abandon nuclear power. In Germany, the share of nuclear electricity has been about one quarter of total generation, i.e. 140 TWh in 2010, and in Switzerland about $40 \%$ of electricity generation. Especially the post-Fukushima decision of Germany to abandon in total $21.5 \mathrm{GW}$ nuclear power by the year 2022 may well happen at the expense of increasing $\mathrm{CO}_{2}$ emissions despite the generous support schemes of renewables: there this currently $12 \mathrm{GW}$ of fossil generation capacity in construction and a further $7 \mathrm{GW}$ under planning. This is in contrast to the recent EU Commission energy roadmap 2050 [13], which aims at practically carbon-free electricity generation in Europe by the year 2050. A large-scale conventional generation plant under construction today is likely to be still in operation in 2050 .

\section{References}

1. L. Bergman, G. Brunekreeft, C. Doyle, N-H. M. von der Fehr, D. M. Newbery, M. Pollitt, P. Régibeau. A European market for electricity? Monitoring European deregulation 2 (CEPR, SNS, 1999)

2. M. Kara, S. Syri, A. Lehtilä, S. Helynen, V. Kekkonen, M. Ruska, J. Forsström. Energy Economics 30193 - 211 (2008)

3. www.tvo.fi/www/page/etusivu_en/

4. www.fortum.com/en/pages/

5. V. Satka. Capacity value of wind power in Finland. Master's Thesis, Aalto University, Espoo, Finland (2010)

6. Council of State. Long-term Climate and Energy Strategy (2008)

7. Federation of Finnish Industries, Federation of Finnish Energy Industries. Electricity demand in 2030 (2009)

8. Federation of Finnish Energy Industries. From challenges to opportunities - vision of carbonneutral electricity and district heating for 2050 (2009)

9. www.tilastokeskus.fi

10. www.ei.se

11. www.ssb.no/en/elektrisitet/

12. www.ens.dk

13. European Commission. Energy Roadmap 2050 COM(2011) 885/2 (2011) 